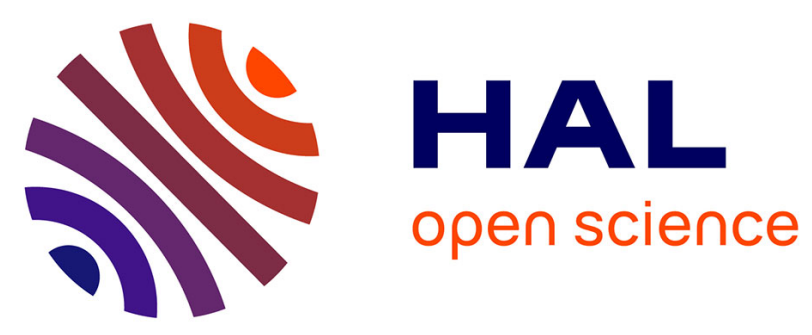

\title{
Diversity and catalytic potential of PAH-specific ring-hydroxylating dioxygenases from a hydrocarbon-contaminated soil.
}

Florence Martin, Laure Malagnoux, Fabien Violet, Jean Jakoncic, Yves Jouanneau

\section{To cite this version:}

Florence Martin, Laure Malagnoux, Fabien Violet, Jean Jakoncic, Yves Jouanneau. Diversity and catalytic potential of PAH-specific ring-hydroxylating dioxygenases from a hydrocarbon-contaminated soil.. Applied Microbiology and Biotechnology, 2013, 97 (11), pp.5125-35. 10.1007/s00253-012-43352. hal-01063652

\section{HAL Id: hal-01063652 https://hal.science/hal-01063652}

Submitted on 15 Sep 2014

HAL is a multi-disciplinary open access archive for the deposit and dissemination of scientific research documents, whether they are published or not. The documents may come from teaching and research institutions in France or abroad, or from public or private research centers.
L'archive ouverte pluridisciplinaire HAL, est destinée au dépôt et à la diffusion de documents scientifiques de niveau recherche, publiés ou non, émanant des établissements d'enseignement et de recherche français ou étrangers, des laboratoires publics ou privés. 
Diversity and catalytic potential of PAH-specific ring-hydroxylating dioxygenases from a hydrocarbon-contaminated soil

Florence Martin $^{1,2}$, Laure Malagnoux ${ }^{1,2}$, Fabien Violet $^{1,2}$, Jean Jakoncic ${ }^{3}$ and Yves Jouanneau $^{1,2}$

${ }^{1}$ CEA, DSV, Laboratoire de Chimie et Biologie des Métaux, F-38054 Grenoble Cedex 9, France.

${ }^{2}$ CNRS UMR 5249, Grenoble, France.

${ }^{3}$ Brookhaven National Laboratory, National Synchrotron Light Source, Upton, NY, USA

Running title : Catalytic potential of PAH-specific RHDs from soil

*Corresponding author:

Yves Jouanneau

LCBM/iRTSV, UMR 5249 CNRS/UJF/CEA

F-38054 Grenoble Cedex 9, France.

Tel. : 33 (0)4.38.78.43.10 ; Fax : 33 (0)4.38.78.54 87

Email : yves.jouanneau@cea.fr 


\section{$1 \quad$ Abstract}

2 Ring-hydroxylating dioxygenases (RHDs) catalyze the initial oxidation step of a range of 3 aromatic hydrocarbons including polycyclic aromatic hydrocarbons (PAHs). As such, they 4 play a key role in the bacterial degradation of these pollutants in soil. Several PCR-based 5 methods have been implemented to assess the diversity of RHDs in soil, allowing limited 6 sequence-based predictions on RHD function. In the present study, we developed a method 7 for the isolation of PAH-specific RHD gene sequences of Gram-negative bacteria, and for 8 analysis of their catalytic function. The genomic DNA of soil PAH degraders was labeled in 9 situ by stable isotope probing, then used to PCR amplify sequences specifying the catalytic 10 domain of RHDs. Sequences obtained fell into five clusters phylogenetically linked to RHDs 11 from either Sphingomonadales or Burkholderiales. However, two clusters comprised 12 sequences distantly related to known RHDs. Some of these sequences were cloned in-frame 13 in place of the corresponding region of the phnAIa gene from Sphingomonas CHY-1 to 14 generate hybrid genes, which were expressed in E. coli as chimerical enzyme complexes. 15 Some of the RHD chimeras were found to be competent in the oxidation of 2- and 3-ring PAHs, but other appeared unstable. Our data are interpreted in structural terms based on 3Dmodeling of the catalytic subunit of hybrid RHDs. The strategy described herein might be useful for exploring the catalytic potential of the soil metagenome and recruit RHDs with new activities from uncultured soil bacteria.

20 Keywords : Dioxygenases ; metagenomic DNA ; catalytic domain ; hybrid enzymes ; bioremediation 
3 Ring-hydroxylating dioxygenases (RHDs) are bacterial metalloenzymes that catalyze the first

4 step in the biodegradation of a variety of aromatic hydrocarbons. Some of them are able to 5 oxidize highly resistant compounds such as polycyclic aromatic hydrocarbons (PAHs)

6 (Jouanneau et al. 2011; Jouanneau et al. 2006). RHDs are two or three-component systems,

7 consisting of an oxygenase which bears the enzyme active site, and specific electron carriers

8 which deliver reductant to the oxygenase for oxygen activation during catalysis (Parales and

9 Resnick 2006). The oxygenase component is most often an heterohexamer $\alpha_{3} \beta_{3}$. Structural 10 studies on representative oxygenases showed that the $\alpha$ subunit is composed of two domains, 11 a Rieske domain that binds a $[2 \mathrm{Fe}-2 \mathrm{~S}]$ cluster, and the catalytic domain containing the 12 substrate-binding site and a mononuclear Fe(II) center where oxygenation of the substrate 13 takes place (Ferraro et al. 2005). Bacterial RHDs form a large enzyme family that can be 14 divided into four to five subgroups based on phylogenetic comparisons of their $\alpha$ subunit 15 amino acid sequences (Kweon et al. 2008; Nam et al. 2001). In this respect, PAH-specific 16 RHDs fall into two clusters of enzymes, those found in Gram-positive bacteria and those 17 found in Gram-negative bacteria (Jouanneau et al. 2011).

18 While the classification of RHDs essentially relies on enzymes found in cultured bacteria, 19 there is compelling evidence that bacterial species recalcitrant to cultivation outnumber 20 cultivable ones by several orders of magnitude in soils and sediments (Cole et al. 2010). 21 Hence, the biodiversity of bacterial enzymes in soil, including RHDs, is certainly much 22 greater than that considered in current classifications, as exemplified by a recent study of 23 dioxygenase genes by a metagenomics approach (Iwai et al. 2010).

24 The diversity of RHDs associated to PAH-polluted sites has been investigated by PCR-based 25 analysis of sequences encoding a portion of the $\alpha$ subunit gene. In marine sediments, RHD 
1 genes appeared to be mainly represented by sequences related to the Cycloclasticus phnAI

2 gene (Lozada et al. 2008), whereas in marine microbial mats subjected to oil contamination,

3 gene sequences similar to nahAc found in Pseudomonads and to nagAc and pahAc found in

4 Betaproteobacteria were mostly detected (Bordenave et al. 2008). A variety of gene sequences

5 related to RHDs from Gram-negative bacteria have been found in soils and sediments

6 polluted by PAHs (Gomes et al. 2007; Ni Chadhain et al. 2006; Park and Crowley 2006; Zhou

7 et al. 2006). As a means to estimate the relative abundance of these genes in soil, quantitative

8 methods based on qPCR have been proposed (Cebron et al. 2008; Ding et al. 2010).

9 Differences in RHD biodiversity observed on PAH-polluted sites might reflect natural

10 variability, but they could also arise from the variety of primer sets used to PCR amplify

11 different portions of the $\alpha$ subunit genes (Iwai et al. 2011).

12 In a recent study, we explored the bacterial diversity of a PAH-contaminated site by stable

13 isotope probing, and found out that Betaproteobacteria were the main microorganisms

14 responsible for the degradation of the tricyclic hydrocarbon phenanthrene in soil (Martin et al.

15 2012). In order to examine the diversity of PAH-specific RHDs on the same experimental

16 site, ${ }^{13} \mathrm{C}$-labeled DNA extracted from soil was used as a template to amplify a large segment

17 of the $\alpha$ subunit gene, extending over the catalytic domain. Phylogenetic analysis revealed

18 that the sequences obtained were related to RHDs found in Sphnigomonadales and

19 Burkholderiales. As a means to further investigate the enzymatic function associated to these

20 microbial sequences, some of them were inserted in place of a gene portion specifying the

21 catalytic domain of the RHD from Sphingomonas CHY-1 (Jakoncic et al. 2007b; Jouanneau

22 et al. 2006). Hybrid genes were expressed together with other components of strain CHY-1

23 enzyme in E. coli, and the activity of the resulting RHDs was assayed in the oxidation of 2-

24 and 3-ring PAHs. This study represents one of the first attempts to link partial sequences 
1 retrieved from soil DNA to enzymatic function using a strategy based on exchange of 2 catalytic domains.

3 
MATERIALS AND METHODS

2 domain (Jakoncic et al. 2007b).

\section{Bacterial strains, plasmids and culture conditions}

Bacterial strains and plasmids used in this study are listed in Tables 1 and 2. E. coli strains were grown in rich medium (Luria-Bertani) at $37^{\circ} \mathrm{C}$ with appropriate antibiotics as previously described (Demaneche et al. 2004).

\section{Primer design and PCR amplification of sequences internal to RHD $\alpha$ subunit genes}

Primers used in this study were designed after analysis of sequence alignments of RHD alpha subunits from representative and well established PAH degraders taken among Gram-negative bacteria. Sequences considered in the alignment are encoded by the following genes : phnAla from Sphingomonas sp. CHY-1 (Demaneche et al. 2004), bphAlf from Sphingobium yanoikuyae B1 (Chadhain et al. 2007), bphAlf from Novosphingobium aromaticivorans (Romine et al. 1999), phnAlf from Sphingomonas sp. LH128 (Schuler et al. 2009), phnAl from Cycloclasticus sp. A5 (Kasai et al. 2003), the phnAc genes from Burkolderia sp. RP007 (Laurie and Lloyd-Jones 1999), Acidovorax sp. NA3 (Singleton et al. 2009), Alcaligenes faecalis AFK2 (accession \# AB024945), Delftia sp. Cs1-4 (formerly Burkholderia Cs1-4; accession \# AY367786), Burkholderia sp. DBT1 (Di Gregorio et al. 2004), and $n d o B$ from Pseuomonas putida NCIB9816 (Simon et al. 1993). Two short, partially conserved sequences were selected for primer design, corresponding to FVCNYHGW and IGETSYR in PhnA1a from Sphingomonas sp. CHY-1. These sequences delimited a portion of the protein (residues 98-412) encompassing the almost entire catalytic

4 One set of degenerate primers was intended to target a wide range of RHD genes from

5 Proteobacteria. The nucleotide sequences of the forward (Phn-RHDf2) and reverse (Phn- 
1 RHDR3) primers were TTCRYBTGCAAYTATCAYGGYTGG and

2 CCYCKRTAVCWKGTYTCKCCRA, respectively. Another pair of primers, with a lower

3 level of degeneracy, was used to specifically amplify sequences relevant to RHDs from

4 Betaproteobacteria. The sequences of the forward and reverse primers were:

5 TTCASYTGCACYTATCACGGCTGG (RHD-Beta-Grp1f) and

6 CCKCKRTARGASGTYTCRCCAA (RHD-Beta-Grp1r). The template was a preparation of

$7 \quad{ }^{13} \mathrm{C}$-labeled DNA obtained through stable isotope probing. The DNA sample was extracted

8 from a soil microcosm incubated for 5 days with $310 \mathrm{ppm}{ }^{13} \mathrm{C}$-phenanthrene, then purified by

$9 \mathrm{CsCl}$ isopycnic ultracentrifugation as previously described (Martin et al. 2012). PCR was

10 conducted with a Tpersonal thermocycler (Biometra) in a final volume of $50 \mu 1$ consisting of

$11100 \mathrm{ng}$ template DNA, $1 \times$ PCR buffer, $1.5 \mathrm{mM} \mathrm{MgSO}_{4}, 200 \mu \mathrm{M}$ of each $\mathrm{dNTP}, 0.3 \mu \mathrm{M}$ of

12 each primer, $1 \mathrm{U}$ of Kod Hot start DNA polymerase (Novagen). Amplification conditions

13 were as follows: $95^{\circ} \mathrm{C}$ for $3 \mathrm{~min}$, then 30 cycles of denaturation for $30 \mathrm{~s}$ at $95^{\circ} \mathrm{C}$, annealing

14 for $20 \mathrm{~s}$ and extension at $70^{\circ} \mathrm{C}$ for $16 \mathrm{~s}$. Annealing was performed at $52^{\circ} \mathrm{C}$ for 10 cycles then

15 at $50^{\circ} \mathrm{C}$ for 10 cycles and finally at $48^{\circ} \mathrm{C}$ for 10 cycles. When the RHD-Beta-Grp1f $/ \mathrm{r}$ primer

16 pair was used, PCR conditions were similar except that annealing was carried out at $63^{\circ} \mathrm{C}$ for

$1720 \mathrm{~s}$ and extension at $70^{\circ} \mathrm{C}$ for $15 \mathrm{~s}$.

\section{Construction of clone libraries and sequence analysis of amplicons}

PCR products obtained with the Phn-RHDf2/R3 primer set were cloned into pSTBlue-1

21 using the perfectly blunt cloning kit (Novagen, Merck). Clones were screened for the 22 occurrence of an insert of the correct size by PCR using the same primer set. A selection of 23 positive clones was grown in a 96-well microtiter plate, resulting in a first library named 24 DcatdioxA. A second library called DcatdioxB was obtained by cloning PCR products 25 obtained with the RHD-Beta-Grp1f/r primers into pJET1.2 (Fermentas). The cloned inserts of 
1 both libraries were subjected to nucleotide sequencing on both DNA strands (as performed by

2 either Beckman Coulter genomics or Eurofins). The resulting sequences were translated, then

3 aligned and compared using Clustal X. Phylogenetic analysis was performed by the neighbor-

4 joining clustering method with bootstrap analysis, using the One-click software available on

5 the www.phylogeny.fr website (Dereeper et al. 2008). The tree was formatted with Treedyn.

6 Nucleotide sequences described in this study were deposited in the EMBL-EBI database

7 under accession numbers HE795402-HE795451 (DcatdioxA library) and HE774402-

8 HE774466 (DcatdioxB library).

9

10 Construction of hybrid RHD genes

11 Hybrid genes were constructed by replacing a portion of the CHY-1 phnAla gene as

follows. First, the phnAlaA2a pair of genes encoding PhnI was subcloned as a XbaI-HindIII

fragment from pSD8 into pUC18 to give pFMA1. In this construction, the resulting PhnI $\alpha$

14 subunit carried a His-tag at the N-terminus. Plasmid pFMA1 was then used to replace a fragment internal to phnAla by an appropriate sequence derived from the DcatdioxA clone library as outlined in supplementary figure S1. To this end, PCR fragments were amplified by using six cloned sequences, U3-18, U3-60, U3-72, U3-89, U3-112 and U3-116 as templates and primers introducing restriction sites for RsrII and AgeI at the 5'- and 3'-end, respectively.

19 The fragments were digested by these two enzymes, and then cloned into corresponding sites of pFMA1 to generate hybrid genes showing a replacement of a $695 \mathrm{bp}$ segment between nucleotide 545 and 1240 of the phnAla coding sequence (Table 2). Two additional constructions were made using U3-16 and U3-124 as templates and primers introducing RsrII and MluI sites at the 5'- and 3'-end, respectively. The fragments were cloned into pFMA1, resulting in hybrid genes with a 580-bp sequence substitution between nucleotide 545 and 1125 (Table 2). All constructions were checked by nucleotide sequencing on both strands. 


\section{Overexpression and in vivo assays of RHD chimeras}

Plasmid pFMA1 and vectors derived thereof carrying hybrid genes (Table 2) were

introduced into strain JM109 together with plasmid pIBA34 by co-transformation. Plasmid

5 pIBA34 carries the phnA3 and phnA4 genes encoding the ferredoxin and reductase

6 components of CHY-1 RHD, respectively. The PhnA4 reductase was His-tagged at the N-

7 terminus. Transformants were grown at $37^{\circ} \mathrm{C}$ until bacterial density reached $1.0\left(\mathrm{OD}_{600}\right)$, then

8 induced with $1 \mathrm{mM}$ isopropyl $\beta$-D-1-thiogalactopyranoside (IPTG) and further incubated at

$925^{\circ} \mathrm{C}$ for about $20 \mathrm{~h}$. Cultures were centrifuged, washed and resuspended to a bacterial

10 density of $2.0\left(\mathrm{OD}_{600}\right)$ in $\mathrm{M} 9$ medium containing $20 \mathrm{mM}$ glucose. Bacterial suspensions were

11 distributed in 2-ml Eppendorf tubes (1ml/tube), in which $0.5 \mu$ mole of PAH had been introduced as a solution in acetone. After solvent evaporation, bacteria were incubated on a rotary shaker at $25^{\circ} \mathrm{C}$ for $6 \mathrm{~h}$. Tubes were centrifuged $2 \mathrm{~min}$ at $12,000 \mathrm{~g}$, then $0.9 \mathrm{ml}$ of

14 supernatant medium was mixed with $9 \mu 1$ of 2,3-dihydroxybiphenyl $(0.1$ or $1 \mathrm{mM}$; Sigma-

15 Aldrich) as an internal standard. The aqueous fraction was extracted with an equal volume of ethyl acetate. Dried extracts were taken up in $0.2 \mathrm{ml}$ acetonitrile and analyzed by GC/MS as n-butylboronate (NBB) derivatives as previously described (Schuler et al. 2008). Anthracene dihydrodiol was instead reacted with a silylation reagent (Silyl-991; Macherey-Nagel). Dihydrodiol derivatives were quantified on the basis of peak area using calibration curves generated with known amounts of naphthalene 1,2-dihydrodiol for NBB products, or anthracene 1,2-dihydrodiol for trimethylsilyl derivatives (Jouanneau et al. 2006). Salicylate hydroxylase activity was assayed as described previously (Demaneche et al. 2004). Briefly, induced cells were resuspended in $10 \mathrm{ml} \mathrm{M} 9$ medium as above, then incubated with $1 \mathrm{mM}$

24 salicylate for $6 \mathrm{~h}$. After pelleting bacteria by centrifugation and ethyl acetate extraction, catechol was detected by GC/MS as a NBB derivative. 


\section{Purification of his-tagged oxygenase components}

The his-tagged PhnI oxygenase produced in JM109(pFMA1), as well as enzyme

4 chimera produced from similar expression systems, were tentatively purified through a 5 procedure inspired from that described previously (Jouanneau et al. 2006), with 6 simplifications. Cultures of recombinant bacteria $(0.8 \mathrm{~L})$ were grown in 2-L flasks to an $\mathrm{OD}_{600}$ 7 of 1 , then supplemented with $50 \mu \mathrm{M} \mathrm{Fe}\left(\mathrm{NH}_{4}\right)_{2}\left(\mathrm{SO}_{4}\right)_{2}$ and induced with $1 \mathrm{mM}$ IPTG at $20^{\circ} \mathrm{C}$ 8 for $20 \mathrm{~h}$. Bacteria were harvested by centrifugation and kept frozen at $-20^{\circ} \mathrm{C}$. Frozen pellets 9 were resuspended in twice the volume of PGE buffer consisting of $25 \mathrm{mM}$ potassium 10 phosphate $\mathrm{pH} 7.5,0.5 \mathrm{M} \mathrm{NaCl}, 5 \%$ glycerol, $5 \%$ ethanol and $2 \mathrm{mM} \beta$-mercaptoethanol. The 11 following steps were performed under anoxic conditions with argon-saturated buffers. After treatment with $0.5 \mathrm{mg} / \mathrm{ml}$ lysozyme for $20 \mathrm{~min}$, suspensions were subjected to ultrasonication for 5 min on ice with a Vibra Cell apparatus operated in pulse mode (Fisher Bioblock Scientific,

14 Illkirch, France). The lysates were centrifuged at 12,000 g for $20 \mathrm{~min}$, and the resulting cell extracts were applied onto small columns $(1.5 \mathrm{ml})$ of immobilized-Co ${ }^{2+}$ affinity chromatography resin (TALON, BD Biosciences Ozyme, France). The columns were washed successively with $15 \mathrm{ml}$ of PGE buffer and $10 \mathrm{ml}$ of PGE containing $10 \mathrm{mM}$ imidazole. The proteins were eluted in approx. $1 \mathrm{ml}$ of PGE lacking $\mathrm{NaCl}$ but containing $0.15 \mathrm{M}$ imidazole and kept frozen in liquid nitrogen.

\section{Biochemical analyses}

Expression of recombinant RHDs in E. coli was analyzed by sodium dodecyl sulfatepolyacrylamide gel electrophoresis (SDS-PAGE) on 10\% slab gels using a SE 260 Mighty

24 Small II system (Hoefer ${ }^{\circledR}$, Inc). Gels were processed and stained as previously described 25 (Jouanneau et al. 2006). For Western blot analysis, proteins were transferred to Hybond C 
1 nitrocellulose membranes (Amersham Biosciences) in a Biometra apparatus as described

2 previously (Jouanneau et al. 1995). Membranes were processed for immunodetection of His-

3 tagged proteins using mice anti-Histag $\operatorname{IgG}$ coupled to horse radish peroxidase at a 1/3000

4 dilution ratio (Sigma-Aldrich). Blots were revealed using a luminescent reagent (ECL;

5 Amersham Biosciences) and a Fusion Fx7 imaging system (Vilbert Lourmat).

6 Protein concentrations were determined using the Bradford reagent with bovine serum 7 albumin as a standard.

8

$9 \quad$ Molecular modeling

10 The crystal structure of the oxygenase component (PhnI) of Sphingomonas CHY-1 11 RHD (PDB code: 2CKF) was used as a template to generate 3D-models for the hybrid 12 enzymes. To this end, all necessary residue replacements were simultaneously performed in 13 the relevant region of the PhnI catalytic domain (between amino acids 185 and 415 of the $14 \alpha$ subunit), using COOT (Emsley et al. 2010). The backbone structure of the catalytic domain 15 was therefore maintained. The position of replaced amino acids was inspected and sometimes 16 adjusted to minimize interactions, using coordinates and electron density maps of the original 17 PhnI structure as guides. Water molecules were not modeled. 


\section{RESULTS}

\section{Isolation of RHD sequences from soil treated with ${ }^{13} \mathrm{C}$-phenanthrene}

In a previous study, we implemented a stable isotope probing approach to identify

PAH degrading bacteria in a hydrocarbon-contaminated soil from a road runoff collecting facility (Martin et al. 2012). Analysis of a ${ }^{13} \mathrm{C}$-labeled DNA fraction purified from soil incubated for 5 days with $310 \mathrm{ppm}{ }^{13} \mathrm{C}$-phenanthrene, showed that phenanthrene degraders were dominated by Betaproteobacteria. Here, we made use of the same DNA fraction to investigate the biodiversity of RHD sequences possibly involved in PAH oxidation. To this end, we employed a PCR-based strategy to amplify a ca 940-bp internal fragment of the alpha subunit gene. The sequences, delimited by nucleotides 291 and 1234 in the phnAla gene from strain $\mathrm{CHY}-1$, extended between two partially conserved regions corresponding to the $[2 \mathrm{Fe}-$ 2S] cluster binding site on the 5'-end, and a region 130-bp from the 3'end (Fig. S1). It covered part of the Rieske-cluster binding domain and the major part of the catalytic domain, including the ligands of the $\mathrm{Fe}(\mathrm{II})$ center at the active site and residues forming the substratebinding pocket (Jakoncic et al. 2007a; Jakoncic et al. 2007b).

Primers used for PCR amplification were designed after alignment of RHD alpha subunits from representative PAH degraders. The Phn-RHDf2/R3 primer set, which showed a high degree of degeneracy, was intended to target all RHD $\alpha$-subunit genes found in a selection of Proteobacteria (see Methods). PCR conditions affording specific amplification of the expected phnAla fragment from strain CHY-1 genomic DNA were applied to recover RHD gene sequences from ${ }^{13} \mathrm{C}$-labeled metagenomic soil DNA. From a total of 96 sequences analyzed, fifty were predicted to encode RHD catalytic domains of the expected size. Among the other clones, two contained RHD sequences bearing a stop codon, thirty-six contained sequences unrelated to RHDs, and eight yielded incomplete sequences. 
Phylogenetic analysis of relevant translated products revealed that the RHD sequences

2 were highly diverse and comparison with counterparts found in the databases showed that

3 they fell into four clusters (Fig. 1). Cluster 1 featured 11 sequences sharing a high level of

4 similarity (86-99\% over 314 amino acids) with the $\alpha$ subunit of previously studied RHDs,

5 including NahA1f from Sphingomonas LH128 (Schuler et al. 2009) and PhnA1a from

6 Sphingomonas CHY-1 (Demaneche et al. 2004). Cluster 2 comprised 17 sequences, which

7 appeared to be more distantly related to known RHDs, as similarity levels did not exceed $67 \%$

8 with the best matching $\alpha$ subunit (PhnA1a from strain CHY-1). Some of the sequences such

9 as U3-89 best matched with PhnA1 from Cycloclasticus A5 (62\%, (Kasai et al. 2003)).

10 Cluster 3 contained 15 sequences showing less that $40 \%$ identity with relevant PAH-specific

11 RHDs. On the other hand, this group was found to share significant sequence similarity with

12 BphA1b from Novosphingobium aromaticivorans (87\%; (Romine et al. 1999)) and AhdA1b

13 from Sphingobium sp. P2 (84\%; (Pinyakong et al. 2003b)). The latter proteins resembled the

$14 \alpha$ subunit of oxygenases mainly found in Spingomonadaceae, which do not catalyze

15 dioxygenase reactions but instead function as salicylate hydroxylases (Jouanneau et al. 2007;

16 Pinyakong et al. 2003b). Finally, 7 sequences were related to RHDs from Burkholderiales,

17 four of which were closely similar and grouped with sequences in cluster 4 (see below).

18 These sequences showed limited similarities with $\alpha$ subunits of known RHDs. In particular,

19 none of the cloned sequences was related to the RHD from Acidovorax NA3 (Singleton et al. 2009), whereas bacteria belonging to this genus were found to be dominant among

21 phenanthrene degraders identified by SIP in the soil of interest (Martin et al. 2012).

Given that PCR amplification from environmental DNA is often subjected to biases

23 resulting in underrepresentation of some sequences in gene libraries, we used a second set of

24 less degenerate primers designed to target the RHD $\alpha$ subunit genes from Betaproteobacteria.

25 PCR amplicons obtained from the same sample of soil ${ }^{13} \mathrm{C}$-DNA as template served to 
1 generate a second library, from which 65 DNA sequences were analyzed. The deduced

2 protein sequences were all related to RHDs from Burkholderiales (Fig. 1), and could be

3 divided into two clusters. The majority of sequences belonged to cluster 4 , and shared less

4 than $65 \%$ identity with the closest match in the UniProt database, the RHD $\alpha$ subunit from

5 Burkhloderia sp. DBT1 (Di Gregorio et al. 2004). Interestingly, this strain initially isolated on

6 dibenzothiophene as sole carbon source was recently shown to degrade phenanthrene and

7 other PAHs (Andreolli et al. 2011), suggesting that its dioxygenase could oxidize these

8 hydrocarbons. The last cluster (cluster 5) consisted of 8 sequences highly similar to the $\alpha$

9 subunit of Acidovorax NA3 RHD (>94\% identity over 314 amino acids)(Fig. 1).

In order to assess the catalytic activity associated to some of the RHD sequences

11 described above, construction of enzyme chimeras was undertaken using the well-described

12 dioxygenase from Sphingomonas CHY-1 as a model.

\section{Construction of hybrid phnAla genes and expression of RHD chimera in E. coli}

In previous studies, we used a 12-kb plasmid (pSD9) for optimal expression of the

PhnI oxygenase from strain CHY-1 in either E. coli (Demaneche et al. 2004) or

Pseudomonas putida (Jouanneau et al. 2006). In order to facilitate the genetic constructions described in this study (Table 2), a smaller expression plasmid was generated by cloning a 2.3-kb DNA fragment including the phnAla and phnA2a structural genes in pUC18 under the lac promoter (Fig. S1). The resulting plasmid (pFMA1) allowed consistent overproduction of PhnI in E. coli JM109, and yielded RHD activity levels about $60 \%$ as high as the BL21(DE3)(pSD9) expression system, when combined with plasmid pIBA34 expressing accessory electron carriers PhnA4 and PhnA3 (data not shown). 
1 by exchange of a 580-bp fragment for the U3-16 and U3-124 sequences (Table 2; see

2 Materials and Methods for details). Resulting plasmids were transferred into strain JM109

3 carrying pIBA34, and expression of RHD chimeras was examined. Analysis of whole cell

4 protein extracts from recombinant E. coli strains by Western blot using His-tag-specific

5 antibodies indicated that hybrid alpha subunits $\left(M_{\mathrm{r}} \approx 52,000\right)$ were produced in all cases (Fig.

6 2A). The second his-tagged protein detected with a $M_{\mathrm{r}}$ of 45,000 was the co-expressed 7 reductase $\mathrm{PhnA} 4$.

Three RHD chimera derived from the U3-18, U3-72 and U3-116 sequences were

9 found to be catalytically active and transformed naphthalene to the corresponding 1,2-

10 dihydrodiol at rates lower than the reference PhnI enzyme expressed under similar conditions

11 (Tables 2 and 3). All other constructions yielded no detectable dioxygenase activity. The

12 RHD derived from U3-18 and U3-116 also transformed phenanthrene, biphenyl and

13 anthracene at relative rates comparable to those found for PhnI (Table 3). The hybrid enzyme

14 made from the U3-72 sequence showed low but significant activity with phenanthrene and

15 biphenyl. Since the deduced amino acid sequences of U3-16 and U3-124 showed high

similarity with the catalytic domain of salicylate hydroxylases, we tested whether the relevant

17 hybrid enzymes would be competent in the hydroxylation of salicylate. No activity was detected suggesting that hybrid enzymes were not stably produced in E. coli, as supported by SDS-PAGE analysis of soluble extracts (data not shown).

Given that RHDs are multi-component enzymes, several reasons might explain the observed poor activity of most of the studied chimeras, including wrong folding of the hybrid alpha subunit, defective assembly of the $\alpha_{3} \beta_{3}$ hexamer or incorrect interaction of the hybrid oxygenase component with the PhnA3 ferredoxin. We first examined whether the enzyme constructions were produced in soluble form in the cytosolic fraction of E. coli. Immunoblot analysis of such fractions indicated that only hybrid RHDs endowed with high activity (U3-18 
1 and U3-116) were detected at levels comparable to PhnI (Fig. 2B). On the other hand, hybrid

2 RHDs displaying little or no activity were barely detected in E. coli cytosol (Fig. 2B, lines 5-

3 7). Since the His-tagged $\alpha$-subunit of these hybrids was found in whole cell extracts (Fig.

$4 \quad 2 \mathrm{~A}$ ), it is likely that they accumulated as inclusion bodies, suggesting that the lack of activity

5 of those hybrid RHDs was primarily due to instability or misfolding.

We then tried to isolate hybrid RHDs by affinity chromatography (IMAC), taking

7 advantage of the His-tag fused at the N-terminus of the $\alpha$ subunit. Only hybrids with high 8 enough dioxygenase activity could be isolated in significant amount. The absorbance

9 spectrum of the U3-116 hybrid isolated in this way was very similar to that of PhnI

10 (Jouanneau et al. 2006), indicating that Fe-S centers were correctly inserted in the protein

11 (data not shown). On the other hand, hybrid RHDs with no activity could not be isolated from

12 E. coli soluble extracts suggesting that these constructions were essentially produced as 13 insoluble proteins.

\section{Structural insights based on 3D modeling of hybrid RHDs}

To further analyze the structural consequences of the exchange of catalytic domain on hybrid RHDs, we took advantage of the known crystal structure of PhnI from strain CHY-1 to perform molecular modeling of the hybrids (Jakoncic et al. 2007b). The 4 hybrids derived from U3-18, U3-60, U3-72 and U3-112 have closely similar alpha subunit sequences since they differ from each other by less than 6 residues (Fig. S2). Compared to PhnI, these hybrids

21 showed 42 or 43 amino acid replacements (Table 2), some of which are likely to perturb 22 intramolecular interactions within alpha subunits because they are located at the interface between the catalytic and Rieske domains. These changes include Met244, which replaces a

24 threonine in PhnI and Lys332, which replaces a serine. In addition, the sequence Val387- 
1 adjacent alpha subunits in PhnI, is replaced by the highly charged Lys-Asp-Arg peptide in the

2 hybrids. Such substitutions might have marked destabilizing effects on the structure of the

3 oxygenase component. However, the U3-18 hybrid RHD displayed reasonable stability,

4 which seems to be correlated with a unique amino acid replacement, a cysteine in position 5409 (Fig S2). In the crystal structure of PhnI, a serine residue is present at this position, which

6 is part of a $\alpha$ helix in the core of the catalytic domain and interacts with main chain $\mathrm{O}$ of

7 Val202 and Phe242. The former residue is part of the catalytic pocket, the latter is found in a 8 nine-stranded antiparallel $\beta$-sheet in the center of the domain. Additionally, Ser409 9 participates in a hydrogen bond network involving three water molecules and extending to Asn295, one of the amino acid forming the substrate-binding pocket next to the active site $\mathrm{Fe}$ 11 atom (Fig. 3). This network is highly conserved across RHDs of known structure. Hence, 12 Ser409 appears to play a critical structural role, and it is clear that a bulkier amino acid in this 13 position would perturb interactions stabilizing the protein. In this respect, the lack of activity 14 of the U3-60 and U3-89 hybrids might be related to the presence in position 409 of an arginine and a tryptophan, respectively. Indeed, by modeling of the serine-to-arginine substitution, we observed large perturbations at positions 203, 241 and 251 and a shift of the beta-sheet impairing interactions between the alpha and beta subunits. On the other hand, the replacement of Ser409 by a cysteine, as observed in the U3-18 and U3-116 hybrids, would not affect the inter- or intradomain interactions, inasmuch the cysteine is expected to adopt a conformation similar to the serine, and $\mathrm{H}$-bonds involving the Ser $\mathrm{O}$ atom in PhnI would be replaced by bonds involving the Cys $\mathrm{S}$ atom (Fig. 3). Nevertheless, it is unclear what could explain the superior stability of the U3-18 hybrid compared to closely similar hybrids, especially those having a serine in position 409.

\section{DISCUSSION}


In this study, we explored the biodiversity of PAH-specific RHDs in a polluted soil by

2 combining DNA-SIP with selective PCR amplification of targeted gene sequences. Our

3 approach involved two successive screening steps, a SIP experiment allowing for the recovery

4 of genomic DNA from soil PAH degraders only, and amplification of a portion of RHD alpha

5 subunit genes encoding the catalytic domain. The set of sequences recovered in this way

6 appeared to depend on the degree of degeneracy of the primers used. With the highly

7 degenerate primer set, a significant proportion of the sequences (33\%) were unrelated to

8 RHDs, but on the other hand, a greater diversity was observed among relevant sequences than

9 when a less degenerate primer set was used (Fig. 1). Most retrieved RHD sequences were

10 relatively distant from known enzymes available in the UniProt database, and were not

11 detected in previous studies targeting PAH-specific RHDs in soil (Cebron et al. 2008; Ding et al. 2010) or marine environment (Lozada et al. 2008). The predominance of unknown RHD

13 sequences is consistent with the finding that the majority of bacteria identified as 14 phenanthrene degraders in the same soil sample were either from uncultured genera or unknown for their ability to degrade PAHs (Martin et al. 2012).

We then searched for correlations between the expected bacterial hosts of RHDs found in this study, and the taxa previously identified as the main phenanthrene degraders based on 16S rRNA sequence analysis. Among Alphaproteobacteria, Sphingomonads were the most abundant degraders, consistent with the occurrence of 11 RHD sequences affiliated to this taxon (cluster 1), representing $22 \%$ of the sequences in the DcatdioxA library. Cluster 2 sequences appeared to be best related to RHDs from Alphaproteobacteria, although the similarity level was relatively low, so their affiliation to another taxonomic group such as the Cycloclasticus genus cannot be ruled out. Cluster 3 sequences are similar to 3-component 24 salicylate hydroxylases, which play a role in the lower part of the PAH degradation pathway 25 (Jouanneau et al. 2007). Since the latter sequences were not included as targets for PCR 
1 primer design, their retrieval was unexpected. Analysis of the cluster 3 sequences indicates

2 that the reverse primer does not match the 3'end. Nevertheless, the high degeneracy of the

3 primer allowed annealing within the 3 '-end of the gene sequences, thus generating products

4 about 100-bp shorter than sequences in other clusters. Interestingly, the genomes of

5 Sphingomonads were found to contain multiple copies of highly similar genes related to

6 cluster 3 sequences (Pinyakong et al. 2003a; Schuler et al. 2009), suggesting that they might

7 be present in higher copy numbers than other catabolic genes in metagenomic DNA from the

8 studied soil. This might account for the relatively high proportion of cluster 3 sequences

$9(30 \%)$ in the Dcatdiox A library.

10 Using a second primer pair targeting Betaproteobacteria RHDs, sequences closely

11 related to Acidovorax RHD were obtained, consistent with the prevalence of this genus among the soil phenanthrene degraders (Martin et al. 2012; Singleton et al. 2005). However,

13 the majority of the sequences in the DcatdioxB library (87\%) showed no clear affiliation.

14 Since uncultured members of the Rhodocyclaceae also appeared as prominent degraders in our previous SIP experiments, we suggest that the sequences of interest (cluster 4) might be specific of this bacterial taxon. Rhodocyclaceae have been detected as potent PAH degraders in other SIP studies (Singleton et al. 2007; Singleton et al. 2006), but no representative strain has been isolated so far. Therefore, no RHD sequence specific for this taxon is yet available. In a second part of this study, we demonstrated the feasibility of constructing RHD chimeras to assess the catalytic activity and substrate specificity associated to partial gene sequences retrieved from soil. Three RHD hybrids were proved competent in the dioxygenation of 2- and 3-ring PAHs, whereas most other hybrids appeared unstable. The reason for this instability is intriguing. Four of them have very similar sequences but variable 24 stabilities. The U3-18, U3-60, U3-72 and U3-112 sequences are almost identical to the 
1 sequence occur at positions where amino acids were neither strictly conserved nor involved in 2 catalytic activity, namely, Val182, Lys195, Gln273, Asn370, Ser409 (Fig. S2). Therefore, the 3 question arises as to why RHD chimeras resulting from a sequence combination between the $4 \alpha$ subunits of two naturally occurring enzymes were so unstable. In this respect, the case of 5 the U3-18 hybrid is interesting in that it showed reasonable stability and activity, and 6 displayed one unique replacement compared to the other three hybrids in position 409. A 7 cysteine is found at this position whereas an arginine occurs in U3-60 and a serine in the other 8 hybrids as well as in most RHD sequences in the databases (Fig. S2). This substitution 9 appeared to be the sole sequence difference between the U3-60 and U3-18 hybrids, and therefore this unique change has drastic effects on the enzyme stability. Structural 11 considerations could predict the strong destabilizing effect of a bulky residue such as arginine in position 409 on the 3D fold of the RHD catalytic component and thus explain the instability of the U3-60 hybrid. On the other hand, the instability of other hybrids with a serine in position 409 could not be interpreted on structural grounds.

During the course of this study, Standfuß-Gabisch reported on the characterization of hybrid biphenyl dioxygenases generated through a similar strategy (Standfuss-Gabisch et al. 2012). Sequences amplified from soil DNA encoded a portion of the catalytic domain similar to that considered in the present work, but diversity was lower as most sequences fell into 2 main clusters and shared $97-100 \%$ identities within clusters and $85-88 \%$ identities between clusters. Hybrid RHDs were constructed using the well-characterized biphenyl dioxygenase from B. xenovorans LB400. Out of 21 hybrid RHDs tested, three were found to be unstable and three were inactive. No obvious correlation was observed between lack of activity and predicted structural changes resulting from amino acid substitutions. The high proportion of active hybrids might be explained by the fact that, in their case, a majority of the hybrids exhibited a catalytic domain closely similar (85-96\% identity) to that of the LB400 enzyme. 
1 In comparison, our constructions carried an inserted domain sharing less than $83 \%$ identity

2 with the corresponding region of the PhnI sequence. Hence, the stability and activity of

3 hybrid RHDs might depend on the relatedness between the sequences to be inserted and that

4 of the recipient enzyme system. Also, for the recovery of active hybrids, one should consider

5 the intrinsic stability of the enzyme system employed to generate hybrids or its propensity to

6 tolerate replacement of a large portion of its catalytic domain. In this respect, RHDs other

7 than PhnI from strain CHY-1 might prove more suitable for the construction of hybrid

8 enzymes with appropriate stability. Finding such enzymes is likely to be a prerequisite to the

9 functional exploration of RHD diversity in soil, based on the exchange of catalytic domains.

11 Acknowledgments

12 F. Martin received a grant from the Rhône-Alpes region. This work was supported by grants

13 from the Centre National de la Recherche Scientifique and the University of Grenoble I. 


\section{$1 \quad$ References}

2 Andreolli M, Lampis S, Zenaro E, Salkinoja-Salonen M, Vallini G (2011) Burkholderia fungorum DBT1: a promising bacterial strain for bioremediation of PAHscontaminated soils. Fems Microbiol Let 319:11-18

Bordenave S, Goni-urriza M, Vilette C, Blanchard S, Caumette P, Duran R (2008) Diversity of ring-hydroxylating dioxygenases in pristine and oil contaminated microbial mats at genomic and transcriptomic levels. Environ Microbiol 10:3201-3211

Cebron A, Norini MP, Beguiristain T, Leyval C (2008) Real-Time PCR quantification of PAH-ring hydroxylating dioxygenase (PAH-RHD alpha) genes from Gram positive and Gram negative bacteria in soil and sediment samples. J Microbiol Meth 73:148159

Chadhain SMN, Moritz EM, Kim E, Zylstra GJ (2007) Identification, cloning, and characterization of a multicomponent biphenyl dioxygenase from Sphingobium yanoikuyae B1. J Ind Microbiol Biotechnol 34:605-613

Cole JR, Konstantinidis K, Farris RJ, Tiedje JM (2010) Microbial diversity and phylogeny: extending from rRNAs to genomes. In: Liu W-T, Jansson JK (eds) Environmental molecular microbiology. Caister Academic Press, Norfolk, UK, pp 1-19

Demaneche S, Meyer C, Micoud J, Louwagie M, Willison JC, Jouanneau Y (2004) Identification and functional analysis of two aromatic ring-hydroxylating dioxygenases from a Sphingomonas strain degrading various polycyclic aromatic hydrocarbons. Appl Environ Microbiol 70:6714-6725

Dereeper A, Guignon V, Blanc G, Audic S, Buffet S, Chevenet F, Dufayard JF, Guindon S, Lefort V, Lescot M, Claverie JM, Gascuel O (2008) Phylogeny.fr: robust phylogenetic analysis for the non-specialist. Nucleic acids res 36(Web Server issue):W465-469 
1 Di Gregorio S, Zocca C, Sidler S, Toffanin A, Lizzari D, Vallini G (2004) Identification of two new sets of genes for dibenzothiophene transformation in Burkholderia sp DBT1. Biodegradation 15:111-123

Ding GC, Heuer H, Zuhlke S, Spiteller M, Pronk GJ, Heister K, Kogel-Knabner I, Smalla K (2010) Soil type-dependent responses to phenanthrene as revealed by determining the diversity and abundance of polycyclic aromatic hydrocarbon ring-hydroxylating dioxygenase genes by using a novel PCR detection system. Appl Environ Microbiol $76: 4765-4771$

Emsley P, Lohkamp B, Scott W, Cowtan K (2010) Features and development of Coot. Acta Cryst D66:486-501

Ferraro DJ, Gakhar L, Ramaswamy S (2005) Rieske business: Structure-function of Rieske non-heme oxygenases. Biochem Biophys Res Commun 338:175-190

Gomes NCM, Borges LR, Paranhos R, Pinto FN, Krogerrecklenfort E, Mendonca-Hagler LCS, Smalla K (2007) Diversity of $n d o$ genes in mangrove sediments exposed to different sources of polycyclic aromatic hydrocarbon pollution. Appl Environ Microbiol 73:7392-7399

Iwai S, Chai BL, Sul WJ, Cole JR, Hashsham SA, Tiedje JM (2010) Gene-targetedmetagenomics reveals extensive diversity of aromatic dioxygenase genes in the environment. Isme J 4:279-285

Iwai S, Johnson TA, Chai B, Hashsham SA, Tiedje JM (2011) Comparison of the specificities and efficacies of primers for aromatic dioxygenase gene analysis of environmental samples. Appl Environ Microbiol 77:3551-3557

Jakoncic J, Jouanneau Y, Meyer C, Stojanoff V (2007a) The catalytic pocket of the ringhydroxylating dioxygenase from Sphingomonas CHY-1. Biochem Biophys Res Commun 352:861-866 
1 Jakoncic J, Jouanneau Y, Meyer C, Stojanoff V (2007b) The crystal structure of the ringhydroxylating dioxygenase from Sphingomonas CHY-1. Febs J 274:2470-2481

3 Jouanneau Y, Martin F, Krivobok S, Willison JC (2011) Ring-hydroxylating dioxygenases involved in PAH biodegradation : structure, function and biodiversity. In: Koukkou AI (ed) Microbial bioremediation of non metals: current research. Caister Academic Press, Norflok, UK, pp 149-175

Jouanneau Y, Meyer C, Jakoncic J, Stojanoff V, Gaillard J (2006) Characterization of a naphthalene dioxygenase endowed with an exceptionally broad substrate specificity toward polycyclic aromatic hydrocarbons. Biochemistry 45:12380-12391

Jouanneau Y, Meyer C, Naud I, Klipp W (1995) Characterization of an $f d x N$ mutant of Rhodobacter capsulatus indicates that ferredoxin I serves as electron donor to nitrogenase. Biochim Biophys Acta 1232:33-42

Jouanneau Y, Micoud J, Meyer C (2007) Purification and characterization of a threecomponent salicylate 1-hydroxylase from Sphingomonas sp. strain CHY-1. Appl Environ Microbiol 73:7515-7521

Kasai Y, Shindo K, Harayama S, Misawa N (2003) Molecular characterization and substrate preference of a polycyclic aromatic hydrocarbon dioxygenase from Cycloclasticus $\mathrm{sp}$ strain A5. Appl Environ Microbiol 69:6688-6697

Kraulis PJ (1991) Molscript: a program to produce both detailed and schematic plots of protein structures. J Appl Cryst 24:946-950

Kweon O, Kim S-J, Baek S, Chae J-C, Adjei M, Baek D-H, Kim Y-C, Cerniglia C (2008) A new classification system for bacterial Rieske non-heme iron aromatic ringhydroxylating oxygenases. BMC Biochem 9:11 
1 Laurie AD, Lloyd-Jones G (1999) The phn genes of Burkholderia sp. strain RP007 constitute a divergent gene cluster for polycyclic aromatic hydrocarbon catabolism. J Bacteriol 181:531-540

4

Lozada M, Mercadal JPR, Guerrero LD, Di Marzio WD, Ferrero MA, Dionisi HM (2008) Novel aromatic ring-hydroxylating dioxygenase genes from coastal marine sediments of Patagonia. BMC Microbiol 8

Martin F, Torelli S, Le Paslier D, Barbance A, Martin-Laurent F, Bru D, Geremia R, Blake G, Jouanneau Y (2012) Betaproteobacteria dominance and diversity shifts in the bacterial community of a PAH-contaminated soil exposed to phenanthrene. Environ Pollut $162: 345-353$

Merritt EA, Murphy ME (1994) Raster3D version 2.0: a programforphotorealistic molecular graphics. Acta Cryst D50:869-873

Moreno-Ruiz E, Hernaez MJ, Martinez-Perez O, Santero E (2003) Identification and functional characterization of Sphingomonas macrogolitabida strain TFA genes involved in the first two steps of the tetralin catabolic pathway. J Bacteriol 185:20262030

Nam JW, Nojiri H, Yoshida T, Habe H, Yamane H, Omori T (2001) New classification system for oxygenase components involved in ring- hydroxylating oxygenations. Biosci Biotechnol Biochem 65:254-263.

Ni Chadhain SM, Norman RS, Pesce KV, Kukor JJ, Zystra GJ (2006) Microbial dioxygenase gene population shifts during polycyclic aromatic hydrocarbon biodegradation. Appl Environ Microbiol 72:4078-4087

Parales RE, Resnick SM (2006) Aromatic ring hydroxylating dioxygenases. In: Ramos JL, Levesque RC (eds) Pseudomonas. vol 4. Springer, pp 287-340 
1 Park JW, Crowley DE (2006) Dynamic changes in nahAc gene copy numbers during degradation of naphthalene in PAH-contaminated soils. Appl Environ Microbiol $72: 1322-1329$

Pinyakong O, Habe H, Omori $\mathrm{T}$ (2003a) The unique aromatic catabolic genes in sphingomonads degrading polycyclic aromatic hydrocarbons (PAHs). J Gen Appl Microbiol 49:1-19

Pinyakong O, Habe H, Yoshida T, Nojiri H, Omori T (2003b) Identification of three novel salicylate 1-hydroxylases involved in the phenanthrene degradation of Sphingobium sp. strain P2. Biochem Biophys Res Commun 301:350 - 357

Romine MF, Stillwell LC, Wong KK, Thurston SJ, Sisk EC, Sensen C, Gaasterland T, Fredrickson JK, Saffer JD (1999) Complete sequence of a 184-kilobase catabolic plasmid from Sphingomonas aromaticivorans F199. J Bacteriol 181:1585 - 1602

Schuler L, Chadhain SMN, Jouanneau Y, Meyer C, Zylstra GJ, Hols P, Agathos SN (2008) Characterization of a novel angular dioxygenase from fluorene-degrading Sphingomonas sp strain LB126. Appl Environ Microbiol 74:1050-1057

Schuler L, Jouanneau Y, Chadhain SM, Meyer C, Pouli M, Zylstra GJ, Hols P, Agathos SN (2009) Characterization of a ring-hydroxylating dioxygenase from phenanthrenedegrading Sphingomonas sp. strain LH128 able to oxidize benz[a]anthracene. Appl Microbiol Biotechnol 83:465-475

Simon MJ, Osslund TD, Saunders R, Ensley BD, Suggs S, Harcourt A, Suen WC, Cruden DL, Gibson DT, Zylstra GJ (1993) Sequences of genes encoding naphthalene dioxygenase in Pseudomonas putida strains G7 and NCIB 9816-4. Gene 127:31-37

Singleton DR, Hunt M, Powell SN, Frontera-Suau R, Aitken MD (2007) Stable-isotope probing with multiple growth substrates to determine substrate specificity of uncultivated bacteria. J Microbiol Meth 69:180-187 
1 Singleton DR, Powell SN, Sangaiah R, Gold A, Ball LM, Aitken MD (2005) Stable-isotope probing of bacteria capable of degrading salicylate, naphthalene, or phenanthrene in a Bioreactor treating contaminated soil. Appl Environ Microbiol 71:1202-1209

Singleton DR, Ramirez LG, Aitken MD (2009) Characterization of a polycyclic aromatic hydrocarbon degradation gene cluster in a phenanthrene-degrading Acidovorax strain. Appl Environ Microbiol 75:2613-2620

Singleton DR, Sangaiah R, Gold A, Ball LM, Aitken MD (2006) Identification and quantification of uncultivated Proteobacteria associated with pyrene degradation in a bioreactor treating PAH-contaminated soil. Environ Microbiol 8:1736-1745

Standfuss-Gabisch C, Al-Halbouni

D, Hofer B (2012) Characterization of biphenyl dioxygenase sequences and activities encoded by the metagenomes of highly polychlorobiphenyl-contaminated soils. Appl Environ Microbiol 78:2706-2715

Yanisch-Perron C, Vieira J, Messing J (1985) Improved M13 phage cloning vectors and host strains: nucleotide sequences of the M13mp18 and pUC19 vectors. Gene 33:103-119

Zhou HW, Guo CL, Wong YS, Tam NFY (2006) Genetic diversity of dioxygenase genes in polycyclic aromatic hydrocarbon-degrading bacteria isolated from mangrove sediments. FEMS Microbiol Lett 262:148-157 


\section{Tables}

2 Table 1: Bacterial strains and some of the plasmids used in this study

\begin{tabular}{|c|c|c|}
\hline Strain or Plasmid & Description/genotype & Reference or source \\
\hline \multicolumn{3}{|c|}{ Escherichia coli Strains } \\
\hline NEB $5-\alpha$ & $\begin{array}{l}\text { fhuA2 } \Delta(\arg F-l a c Z) U 169 \text { phoA } \text { glnV44 } \Phi 80 \Delta \text { (lacZ)M15 } \\
\text { gyrA96 recAl relA1 endA1 thi-1 hsdR17 }\end{array}$ & New England Biolabs \\
\hline JM109 & $\begin{array}{l}\text { recAl supE44 endAl hsdR17 gyrA96 relAl thi-1 } \Delta(\text { lac-proAB }) \\
\mathrm{F}\left(\text { TraD36 proAB }{ }^{+} \text {lacl } I^{q} \text { lacZ } \Delta \mathrm{M} 15\right)\end{array}$ & (Yanisch-Perron et al. 1985) \\
\hline \multicolumn{3}{|l|}{ Plasmids $^{a}$} \\
\hline pSD8 & pET $15 b$ carrying phnAlaA2a from strain CHY-1 & (Demaneche et al. 2004) \\
\hline pIZ1036 & $\mathrm{Km}^{\mathrm{R}}$, broad range expression plasmid derived from pBR1MCS-2 & (Moreno-Ruiz et al. 2003) \\
\hline pIBA34 & pIZ1036 carrying phnA3 and phnA4 from strain CHY-1 & Jouanneau, unpublished \\
\hline pUC18 & $\mathrm{Amp}^{\mathrm{R}}$, cloning plasmid & (Yanisch-Perron et al. 1985) \\
\hline pFMA1 & pUC18 carrying phnAlaA2a & This study \\
\hline
\end{tabular}

${ }^{a}$ Other plasmids constructed in this study are listed in Table 2 
1 Table 2 : Characteristics of chimerical RHDs and plasmids used for heterologous expression

2

\begin{tabular}{lcccc}
\hline Sequence & $\begin{array}{c}\text { Insert length } \\
(\mathrm{bp})\end{array}$ & $\begin{array}{c}\text { No of aa substitutions } \\
\text { in the exchanged } \\
\text { domain }^{\mathrm{a}}\end{array}$ & $\begin{array}{c}\text { Expression } \\
\text { plasmid }\end{array}$ & $\begin{array}{c}\text { RHD activity } \\
(\%)\end{array}$ \\
\hline U3-116 & 695 & 39 & pFMA2 & 49 \\
U3-60 & 695 & 42 & pFMA3 & nd \\
U3-72 & 695 & 42 & pFMA4 & 0.26 \\
U3-89 & 695 & 104 & pFMA5 & nd \\
U3-112 & 695 & 43 & pFMA12 & nd \\
U3-18 & 695 & 43 & pFMA13 & 34 \\
U3-16 & 580 & 133 & pFMA6 & nd \\
U3-124 & 580 & 133 & pFMA7 & nd
\end{tabular}

$3{ }^{\mathrm{a}}$ Numbers refer to amino acid changes compared to the corresponding region of PhnA1a

$4 \quad{ }^{\mathrm{b}}$ Activities were determined with naphthalene as substrate and calculated as percentages of 5 the activity measured with the reference strain carrying pFMA1. nd means not detected. 
1 Table 3 : Relative activity of hybrid dioxygenases with 2- and 3-ring PAHs

2

\begin{tabular}{|l|ccccccc|}
\hline \multicolumn{1}{|c}{ PAH } & Naphthalene & \multicolumn{2}{c}{ Biphenyle } & \multicolumn{2}{c|}{ Phenanthrene } & \multicolumn{2}{c|}{ Anthracene } \\
Hybrid & $\mathrm{mU}^{\mathrm{m} l^{\mathrm{a}}}$ & $\mathrm{mU} / \mathrm{ml}$ & $\%^{\mathrm{b}}$ & $\mathrm{mU} / \mathrm{ml}$ & $\%$ & $\mathrm{mU} / \mathrm{ml}$ & $\%$ \\
\hline PhnI & $3020(230)$ & $840(30)$ & 28 & $1300(260)$ & 43 & $295(20)$ & 9.4 \\
U3-116 & $1480(60)$ & $350(3)$ & 24 & $550(25)$ & 37 & $70(1)$ & 4.8 \\
U3-18 & $1030(20)$ & $150(40)$ & 15 & $447(30)$ & 43 & $21.8(1)$ & 2.1 \\
U3-72 & $7.83(1)$ & $3.68(0.6)$ & 47 & $5.25(0.8)$ & 67 & $1.73(0.16)$ & 22 \\
\hline
\end{tabular}

${ }^{a}$ One milliunit of activity $(\mathrm{mU})$ is the amount of enzyme that produced one pmol of

4 dihydrodiol per hour at $25^{\circ} \mathrm{C}$ under the defined assay conditions. Numbers in parenthesis are 5 standard deviations.

$6 \quad{ }^{\mathrm{b}}$ Percentages were calculated relative to the activity measured with naphthalene as substrate. 


\section{$1 \quad$ Figure legends}

2

3 Figure 1 : Phylogenetic tree of predicted partial sequences of RHD alpha subunits from soil

subjected to DNA-SIP. Sequences were from two clone libraries obtained by PCR amplification of target RHD genes using labeled DNA extracted from soil treated with ${ }^{13} \mathrm{C}$ phenanthrene for 5 days. Alignment was performed on a common portion of the translated sequences (corresponding to residues 98-411 of PhnA1a) encompassing the catalytic domain of RHD $\alpha$-subunits. Only 47 of the 50 RHD sequences of the DcatdioxA library were considered in the alignment. Five clusters of related sequences were defined (see text). Triangles represent groups of sequences sharing $>97 \%$ identity, with sequence number per group indicated on the left. Arrows designate sequences used for the construction of hybrid RHDs. Two labels present at the end of a branch (i.e. U3_72 U3_6) means that two identical sequences were found at this position. Relevant accession numbers are indicated.

Figure 2 : Immunoblot analysis of protein cell extracts from strain JM109 expressing hybrid RHDs.

Panel A: whole cell extracts prepared by lysing cells in SDS mix 10 min at $99^{\circ} \mathrm{C}$. Protein loading in each lane was adjusted based on equal bacterial density $\left(\mathrm{OD}_{600}\right)$ as measured prior to cell lysis. Lane 1 : non-induced cells carrying pFMA13 (U3-18); lane 8: purified ht-PhnI, $0.2 \mu \mathrm{g}$. Panel B: Cytosolic fractions prepared by cell ultrasonication and centrifugation. Lanes were loaded with $6 \mu \mathrm{g}$ (lanes 2-4) or $12 \mu \mathrm{g}$ (lanes 5-7) of proteins. Lanes 1 and 8 were loaded with 0.3 and $0.1 \mu \mathrm{g}$ of purified ht-PhnI, respectively. Other lanes were loaded with extracts from cells expressing PhnI (lane 2) or the following hybrid RHDs; lane 3, U3-116 ; lane 4, U3-18 ; lane 5, U3-60 ; lane 6, U3-72 ; lane 7, U3-112. Western blots were revealed 
1 with anti-Histag antibodies. The second band detected with $M_{\mathrm{r}} \approx 45,000$ is the reductase ht-

2 PhnA4 co-expressed in JM109.

3

4 Figure 3 : Close up view of the hydrogen bond network involving Ser409 and its connections

$5 \quad$ with residues at the active site of Phn1.

6 Ser409 is involved in a hydrogen bond network (red dashed lines) involving two water

7 molecules, and extending to Asn295, a residue lining the catalytic pocket. It is connected

8 through its hydroxyl group to the carbonyl of Val202 and Phe242. The network also includes

9 the Gly203-Asp204 dipeptide, where Asp204 is thought to be responsible for electron transfer

10 between the Rieske center of the adjacent alpha subunit and the catalytic site. The covalent

11 bonds between active site Fe atom and its three ligands are shown as green dashed lines. An

12 indole molecule is represented inside the substrate-binding site. The figure was prepared with

13 Molscript (Kraulis 1991) and Raster3D (Merritt and Murphy 1994).

14 
NahAc_ND6_AAP44288 BB10

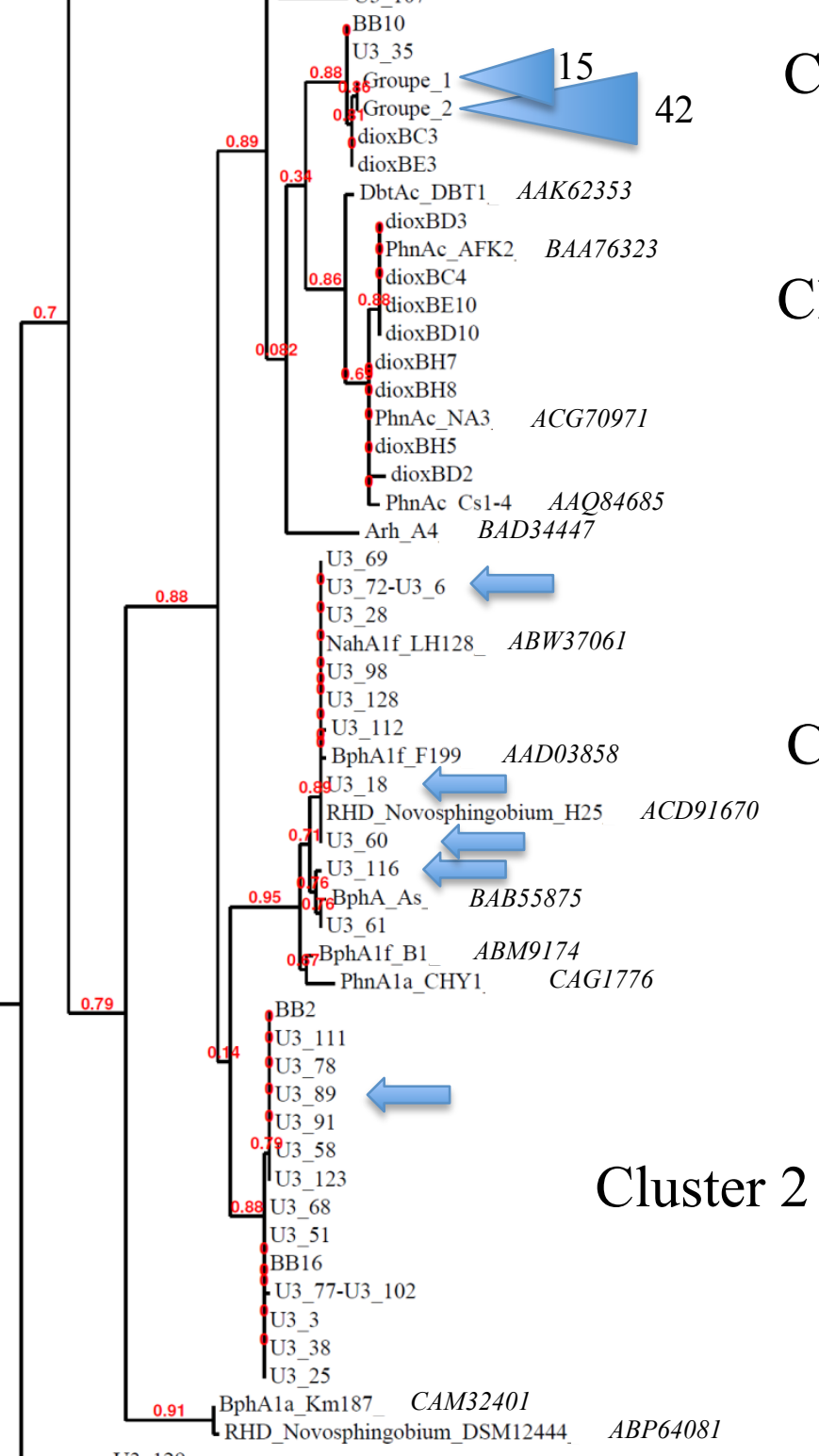

Cluster 4

\section{Cluster 5}

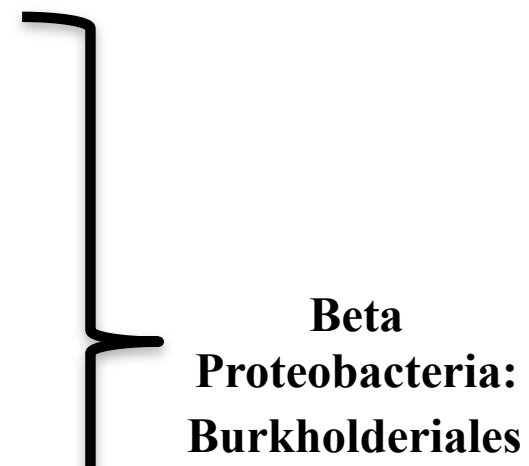

Cluster 1

Alpha proteobacteria: Sphingomonadales

U3_129

U3 47

U3_ 83

$\mathrm{BB} 18$

U3_32

${ }_{\mathrm{r}} \mathrm{U} 3 \mathrm{3}-109$

[U3_16-U3_44

U3_124

$=$

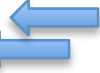

Cluster 3

U3 56

BB20

U3_52

U3_43 


$$
\begin{aligned}
& \begin{array}{llllllll}
1 & 2 & 3 & 4 & 5 & 6 & 7 & 8
\end{array} \\
& A==\pi-5=-
\end{aligned}
$$

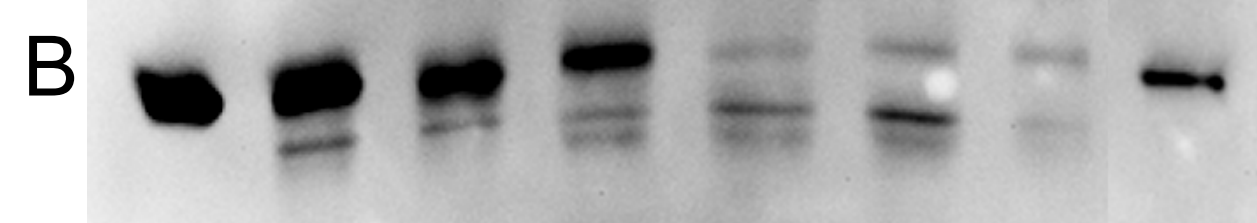

Fig. 2: Martin et al 


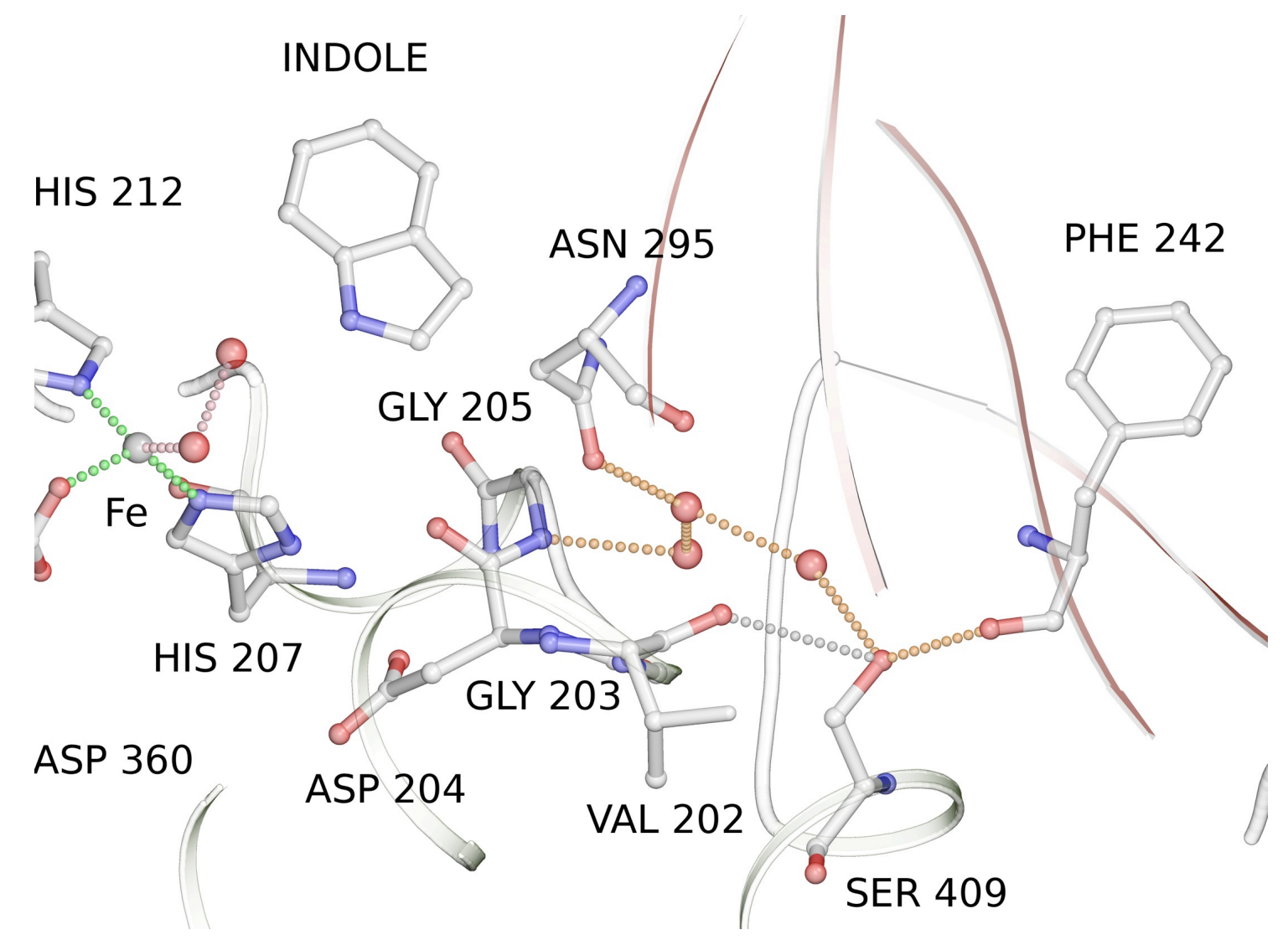

Fig. 3: Martin et al. 